\title{
A survey of practices of tunnel preparation among dentists who attended the 100th FDI Annual World Dental Congress
}

\begin{abstract}
Objective: To study the practice of tunnel restoration (TR) among dentists who attended the 100th World Dental Federation (FDI) Annual World Dental Congress (AWDC).

Methods: An anonymous questionnaire was administered to a sample of 150 dentists who attended the 100th FDI AWDC in 2012. The participants were asked about TR and their practice of TR. They were also asked their years of dental practice and the country they received their dental training.

Results: Fifteen respondents were not performing restoration and they were excluded from analysis. Most respondents (123/135) practiced general dentistry. Their basic dental training was from 46 countries and regions. Most of them $(N=117,87 \%)$ knew about TR, and 53\% $(N=71)$ practiced it. There were 12 dentists (9\%) performed more than 10 TRs in the past 12 months. Practice of TR among dentists who graduated more than 10 years ago was more common (Odd ratio 5.87 - 5.98) than those who graduated less than 3 years.
\end{abstract}

Conclusion: The current study found about half of the surveyed dentists practiced TR although most of them knew it. Only a few dentists performed TR frequently. TR was performed more frequent among dentists who had more than 10 years of clinical experience. 


\section{Introduction}

Dental treatment is moving toward a more conservative, preventive based approach since GV Black described the "extension for prevention" approach. ${ }^{1}$ One methodological approach is the tunnel preparation and tunnel restoration (TR). The tunnel preparation was introduced more than half a century ago to restore interproximal dental caries of a primary molar tooth by accessing the carious lesion on the occlusal surface below the marginal ridge. ${ }^{2}$ The main advantage of tunnel restoration (TR) over the conventional box or slot preparation includes being more conservative and increasing tooth integrity and strength by preserving the marginal ridge. ${ }^{3}$

Recent advances in technology such as the LED handpieces and the use of magnifying loupes enhance the visibility of fine detailed operative dentistry. Galilean loupes provide a high resolution viewing with a wide and deep viewing field during operative treatment. Some high quality loupes use micro-sized optics that are made from the finest grade glass to deliver unprecedented clarity and sharpness throughout the entire field. The advent of digital radiography has improved quality of the dental imaging ${ }^{4}$ and reduced the radiation which could facilitate earlier diagnosis of interproximal caries and closer monitoring of post-treatment success. $^{5}$

The new generation of restorative materials has improved mechanical properties. Glass ionomer cement bonds to enamel and dentine and releases fluorides, and thus, could be a material of choice for tunnel preparation. With the successful development of glass ionomer cements, some clinicians advocated its use in TR. ${ }^{6,7}$ Clinical studies performed before 2000 showed that the success rate for tunnel restorations with glass ionomer was 57-90\% up to three years, with the median survival rate of 6 years. ${ }^{8}$ The longest follow up was 7 years and the success rate was $50 \% .{ }^{9}$ However, Kinomoto et $\mathrm{al}^{10}$ reported the 2-year clinical success rate of composite tunnel restorations was $96 \%$, and there is no significant difference with that of conventional composite slot restoration. Composite resin has superior mechanical strength than glass ionomer cement and it bonds to enamel and dentine and serves as a good material for final direct restorations. Silver amalgam can also be used as it offers good strength and is easy to handle. Although TR is very technique sensitive, ${ }^{11}$ it could be a solution to restore proximal carious lesions if the dentist performs cautious case selection and skillful implementation of tunnel preparation and restoration. Although there are papers that describe the clinical 
technique of TR, ${ }^{12}$ there is a paucity of knowledge regarding its use among practicing dentist.

A survey found that, in 2009 only $7 \%$ of dentist would treat a proximal caries restricted to enamel compared to $66 \%$ in 1983 and $18 \%$ in $1995 .{ }^{13}$ This study also demonstrated a reduction in the use of TR. However, when TR was being used there was a shift from using GIC to composite resin as the material of choice. A recent study found that a premolar with composite TR and 2.5 millimeters of marginal ridge was equally as strong as a sound tooth. ${ }^{14}$ Additionally, a recently published case study described a method to perform TR with flowable composite and packable composite without light curing between. ${ }^{15}$ Clearly, there is an improvement in dental techniques which may assist dentists using the TR technique. The current study is a survey of dentists who attended the World Dental Federation (FDI) to evaluate the utilization of tunnel preparation technique among dentists.

\section{Method}

A questionnaire was delivered to a sample of 150 dentists who attended the FDI Annual World Dental Congress 2012 during 29 Aug to 1 Sep 2012 in Hong Kong. Fifteen dental students were recruited and each of them were instructed to randomly invite 10 dentists to participate in this questionnaire survey. The participants were given an invitation letter to join this survey, and an information sheet which had a brief introduction with photographs regarding two clinical cases on TR (Figure 1). Participant dentists were then asked to complete an anonymous questionnaire which consisted of 9 closed end questions (Table 1). Chi square test was performed to study the association of the practice of TR to dentist's year of dental practice and their hours of continuing dental education in the past 12 months. Binary logistic regression was used to examine practice of tunnel restoration related to the dentist's year of dental practice. The cut-off value of statistical significance was chosen to be 0.05 .

\section{Results}

Among the 150 questionnaires collected, 15 respondents were not performing restoration and they were excluded from the subsequent analysis. Among the 135 respondents who performed restoration, 123 of them practiced general dentistry (Table 1). Their basic dental training was from 46 different countries and regions all over the world. Most of them $(\mathrm{N}=117$, $87 \%)$ knew about tunnel preparation, but only about half $(\mathrm{N}=71 ; 53 \%)$ practiced TR. Only one third $(\mathrm{N}=44 ; 33 \%)$ of surveyed dentists performed TR within the last 6 months and less than 
one tenth $(\mathrm{N}=12 ; 9 \%)$ of them performed more than 10 restorations in the past 12 months.

Two third of the respondents ( $\mathrm{N}=89 ; 66 \%$ ) received more than 15 hours of continuing education in the past 12 months. Similarly, about two thirds of the dentists $(\mathrm{N}=89,66 \%)$ practiced dentistry for more than 10 years. The dentists' practice of TR according to their years of dental practice is shown in Table 2. Results of logistic regression found that practice of TR among dentists who graduated more than 10 years was more common (Odd ratio $5.87-5.98$ ) than those graduated less than 3 years (Table 3 ).

\section{Discussion}

FDI was founded in 1900 as Fédération Dentaire Internationale in Paris, France and is one of the world's oldest existing health profession organizations. ${ }^{16}$ It serves as the principal representative body for more than 1 million dentists from approximately 200 national dental associations. FDI is actively engaged in developing health policy and continuing education programs, speaking as a unified voice for dentistry in international advocacy, and supporting member associations in oral health promotion activities worldwide. The 100th Anniversary FDI Annual World Dental Congress was a unique event in the 2012 dental calendar, with international outreach and a truly global audience of more than 10,000 visitors. ${ }^{17}$

The current study evaluated the use of TR among practicing dentists who attended an international congress. Dentists were actively recruited to participate in the survey and it is a limitation of the study that a non-probability sampling method was used which did not produce randomized sample. Degree of generalizability is also problematic with this recruitment method. Further studies are necessary to extrapolate the findings for a target population of dentists. However, the response from these more than hundred participants can provide useful information on the practice profile of TR and this study can be considered as a pilot study.

While it is interesting to reveal the practices of dentists who were trained from almost 50 different countries or regions all over the world, the results should be interpreted with caution because the dentists attending the conference could be different from practicing dentists in the community. Dentists who attended the international conference may be more active in pursuing continuing education opportunities and may be more likely to seek conservative and beneficial solutions to patient needs. This was reflected in the surveys as many respondents had more than 
15 hours of continuing dental education in the past 12 months and they had more than 10 years of clinical practice experience. This study found only half of them practice TR although most of them knew about the existence of this procedure. Sundberg et al ${ }^{18}$ reported that about half of the dentists preferred TR whereas approximately a quarter chose saucer-shaped preparations and the rest preferred traditional Class II preparations. However, a survey in Norway found that tunnel preparation was only practiced by $4 \%$ of the dentists in Norway. ${ }^{19}$ These findings are similar to those of the current study where less than $10 \%$ of the dentists had performed more than 10 tunnel restorations in the last 12 months. The practice of TR may be overestimated in the current study because selected dentists all attended a major continuing education conference.

A recent review of the clinical studies found conflicting success rate. ${ }^{11}$ The reviewed found that the clinical success rate after 3 years varied from $10 \%$ to $100 \%$, whereas the longterm clinical studies reported the success rate varied from $46 \%$ to $85 \%$ after 8 years. Tunnel restoration is highly technique-sensitive and operator's skill was a significant factor in success. Selecting suitable case for tunnel restoration enhances esthetics and minimizes tooth damage, thus increases patient satisfaction. ${ }^{20}$ Decisions on how a dentist will manage an interproximal carious lesion are complex and dependent on numerous factors. The contemporary dental practice emphasizes in early diagnosis and conservative treatment. ${ }^{5}$ Fluoride varnishes is advocated to remineralise or arrest enamel carious lesion. ${ }^{21}$ A study among Japanese dentists found that even the decision to treat varied a great deal between clinicians. ${ }^{22}$ That study found that factors such as level of caries risk of the patient, gender of the dentist, practice setting and city population were significant factors affecting the decision.

Additionally, studies have demonstrated that caries tends to be underestimated in radiographs. ${ }^{4}$ Even after proximal caries is detected on a radiograph, research has shown that interpretation of the clinician varies a great deal ${ }^{13}$ and the final decision whether to surgically intervene or not is complex and dependent on many factors. Once the decision is made to surgically treat the caries, the dentist also has a variety of treatment options in method and material.

TR was introduced more than 50 years ago and fits the contemporary concepts of minimal intervention dentistry. However, the operative procedure for TR is very technique sensitive. Some dentists considered both tunnel and proximal box/slot preparations will remove similar amounts of tooth substance. For dentists who have no training or are inexperienced, 
there is a greater risk of pulp damage in tunnel preparations. It is not always the most conservative or safest preparation method and case selection is very important. The success rate reported before 2000 was not very high. However, recent studies reported promising results. Wang and Yang ${ }^{23}$ followed up 35 tunnel restorations for 2 years and the rate of success was $100 \%$. The success of TR has improved with the advances in dental materials, the introduction of LED miniature dental hand piece and high quality magnifying loupes. Tunnel preparations are conservative preparations that can be used effectively particular in older patients. ${ }^{24} \mathrm{TR}$ could be a useful restorative technique to conserve the marginal ridge and hence the mechanical strength of the tooth restored, however, the current study indicates that relatively few dentists take advantage of the benefits of TR. In the current study, the participants were mostly dentists committed to continuing dental education. However, the results found that only about half of them used TR in their clinical practice. The current study also demonstrated that, while substantial number of dentists were not practicing TR, those who used the technique would use it relatively frequently.

Tunnel preparation is technique sensitive and can be very challenging to prepare, particularly for mesial caries lesions due to orientation of the handpieces, more posterior tooth and for the inexperienced clinicians. If the marginal ridge becomes undermined it can increase the risk of fracture. Ji et al ${ }^{14}$ reported the strength of the tooth with TR would be comparable to sound tooth if 2.5 millimeters of the marginal ridge is retained. If caries turns out to be more extensive than predicted or the marginal ridge is at risk of fracture, then the tunnel preparation can be converted to a conventional design. With the advances in resin composite, it has become the restorative material preferred by majority of the dentist. ${ }^{19}$ Ebert et al ${ }^{15}$ suggested a novel approach for filling tunnel-prepared teeth with flowable composites followed by packable composite to achieve a superior filling of the preparation.

Thorough removal of caries can be another important challenge for the clinician planning to use TR. Dr John McLean, who promoted tunnel preparations widely, devised his own hand instruments in an attempt to obtain better access and clean caries-free proximal cavity margins in open tunnels. A long and small excavator can also remove decay efficiently around the margin. If the access is obstructed by inadequate lighting, there can be insufficient caries removal which will lead to failure of the restoration. Pyk and Mejara ${ }^{25}$ reported that caries which was detected clinically or radiographically adjacent to the tunnel restoration was the commonest cause of failure of tunnel restoration. The limited access may also increase the risk 
of pulpal damage during mechanical caries removal. Papa et al ${ }^{26}$ reported that tunnel preparation often invaded to within $1.0 \mathrm{~mm}$ of the pulp, and thus, measures for pulpal protection such as use of adequate lighting and magnifying loupes in preparation and bio-compatible protective liner is very important.

A 2012 study found that the success rate for class II direct restorations with modern composites was $90 \%$ after ten years. ${ }^{27}$ Since a class II replaces the marginal ridge which the TR attempts to protect, it may be possible that the strength and longevity of modern composites may have reduced the need for conservative TR. A recent study found that the median life-span of all dental restorations was 11.7 years ${ }^{28}$ with a large amount of variation between different health centers and different teeth in the study. More research is necessary to consider the longevity of TR and those findings must be weighed against each clinical case in the decision to choose TR as the treatment of choice. It is recommended dentists should be trained and learn how to do TR before they perform TR in their patients.

\section{Conclusion}

This study found that about half of the surveyed dentists practiced tunnel restoration although most of them knew about the technique. Only one third of the dentists performed tunnel restoration within the last 6 months and a few $(9 \%)$ performed more than 10 restorations in the past 12 months. Tunnel restoration was performed more frequently among dentists who had more than 10 years of clinical experience. 


\section{References}

1. Osborne JW, Summitt JB. Extension for prevention: is it relevant today? Am J Dent 1998;11:189-96.

2. Ratledge DK, Kidd EA, Beighton D. A clinical and microbiological study of approximal carious lesions. Part 1: the relationship between cavitation, radiographic lesion depth, the site-specific gingival index and the level of infection of the dentine. Caries Res 2001;35:3-7.

3. Wiegand A, Attin T. Treatment of proximal caries lesions by tunnel restorations. Dent Mater 2007;23:1461-7.

4. Bin-Shuwaish M, Dennison JB, Yaman P, Neiva G. Estimation of clinical axial extension of Class II caries lesions with ultraspeed and digital radiographs: an in-vivo study. Oper Dent 2008;33:613-21.

5. Chu CH, Lo EC, You DS. Clinical diagnosis of fissure caries with conventional and laser-induced fluorescence techniques. Lasers Med Sci 2010;25:355-62.

6. Hunt PR. A modified Class II cavity preparation for glass ionomer restorative materials. Quintessence Int 1984;15:1011-8.

7. Knight GM. The tunnel restoration--nine years of clinical experience using capsulated glass ionomer cements. Case report. Aust Dent J 1992;37:245-51.

8. Nicolaisen S, von der Fehr FR, Lunder N, Thomsen I. Performance of tunnel restorations at 3-6 years. J Dent 2000;28:383-7.

9. Hasselrot L. Tunnel restorations in permanent teeth. A 7 year follow up study. Swed Dent $J$ 1998;22:1-7.

10. Kinomoto Y, Inoue Y, Ebisu S. A two-year comparison of resin-based composite tunnel and Class II restorations in a randomized controlled trial. Am J Dent 2004;17:253-6.

11. Chu $\mathrm{CH}$, Mei ML, Cheung C, Nalliah RP. Restoring proximal caries lesions conservatively with tunnel restorations. Clin, Cosmet Investig Dent 2013 (accepted fot publication).

12. Ratledge DK, Kidd EA, Treasure ET. The tunnel restoration. Br Dent J 2002; 193:5016.

13. Gordan VV, Garvan CW, Heft MW, Fellows JL, Qvist V, Rindal DB, et al. Restorative treatment thresholds for interproximal primary caries based on radiographic images: findings from the Dental Practice-Based Research Network. Gen Dent 2009;57:654-63; quiz 64-6, 595, 680 . 
14. Ji W, Chen Z, Frencken JE. Strength of tunnel-restored teeth with different materials and marginal ridge height. Dent Mater 2009;25:1363-70.

15. Ebert J, Frankenberger R, Petschelt A. A novel approach for filling tunnel-prepared teeth with composites of two different consistencies: a case presentation. Quintessence Int 2012;43:93-6.

16. FDI World Dental Federation FDI. About us: FDI World Dental Federation. [Online]. [cited 2013 Jan 1]; Available from: URL: http://www.fdiworldental.org/aboutus;jsessionid=9F0BBC3DC48B4338639C696CC12A6172.

17. FDI Annual World Dental Congress 2012. Home page: FDI Annual World Dental Congress 2012 [Online]. Available from: URL: http://www.fdicongress.org/home;jsessionid=F4F187248CD89750FB607D21BAB8F 911.

18. Sundberg H, Mejare I, Espelid I, Tveit AB. Swedish dentists' decisions on preparation techniques and restorative materials. Acta Odontol Scand 2000;58:135-41.

19. Vidnes-Kopperud S, Tveit AB, Espelid I. Changes in the treatment concept for approximal caries from 1983 to 2009 in Norway. Caries Res 2011;45:113-20.

20. Chu $\mathrm{CH}$, Yeung CY, Lo EC. Monitoring patient satisfaction with university dental services under two fee-paying systems. Community Dent Oral Epidemiol 2001;29:3908.

21. Chu CH, Mei ML, Lo EC. Use of fluorides in dental caries management. Gen Dent 2010;58:37-43; quiz 4-5, 79-80.

22. Kakudate N, Sumida F, Matsumoto Y, Manabe K, Yokoyama Y, Gilbert GH, et al. Restorative treatment thresholds for proximal caries in dental PBRN. J Dent Res 2012;91:1202-8.

23. Wang Y, Yang PS. [Clinical evaluation of tunnel-restoration]. Shanghai Kou Qiang Yi Хие 2003;12:7-8.

24. Chalmers JM. Minimal intervention dentistry: part 2. Strategies for addressing restorative challenges in older patients. J Can Dent Assoc 2006;72:435-40.

25. Pyk N, Mejare I. Tunnel restorations in general practice. Influence of some clinical variables on the success rate. Acta Odontol Scand 1999;57:195-200.

26. Papa J, Cain C, Messer HH, Wilson PR. Tunnel restorations versus class II restorations for small proximal lesions: a comparison of tooth strengths. Quintessence Int 1993;24:93-8. 
27. Heintze SD, Rousson V. Clinical effectiveness of direct class II restorations - a metaanalysis. J Adhes Dent 2012;14:407-31.

28. Suni J, Vahanikkila H, Pakkila J, Tjaderhane L, Larmas M. Review of 36,537 Patient Records for Tooth Health and Longevity of Dental Restorations. Caries Res 2013;47:309-17. 


\section{Figure 1 Introduction of tunnel restoration}

Tunnel restoration can be an esthetic and conservative dental treatment to restore proximal dental caries in posterior teeth. It is however more technique sensitive than conventional proximal (class II) restoration. Thus some dentists have concern if this method increase failure rate due to inadequate caries removal, pulpal damage, marginal fracture or leakage, etc. Attached are photos of two clinical cases performed using Tunnel restorations with bonded silver amalgam and glass ionomer/composite resin to restore distal caries on a lower first molar.

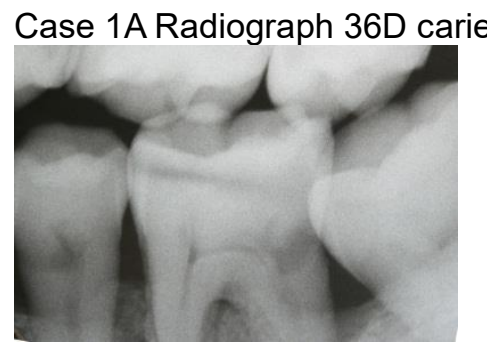

Case 1B Rubber dam isolation

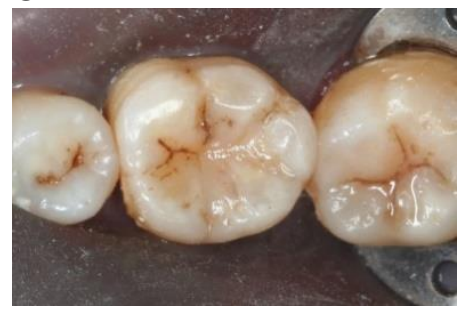

Case 1C Tunnel access

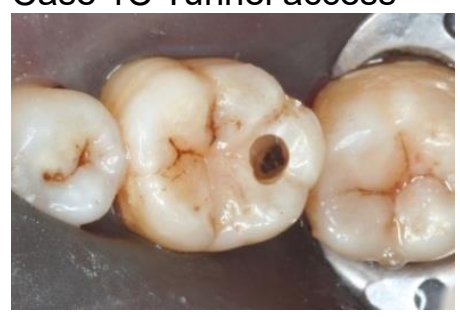

Case 1D Finished restoration

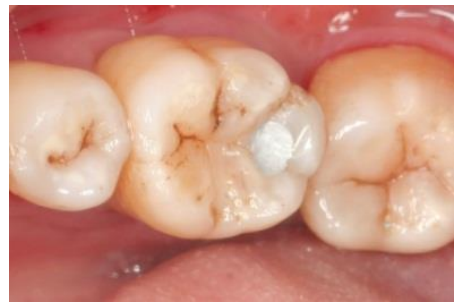

Case 1E Review radiograph

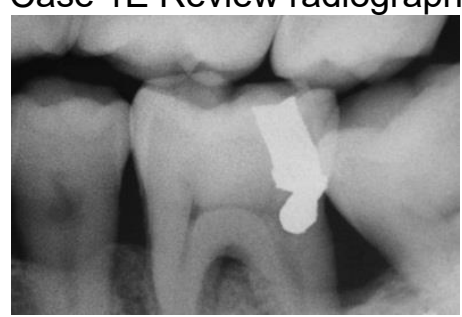

Case 2A Radiograph 36D caries

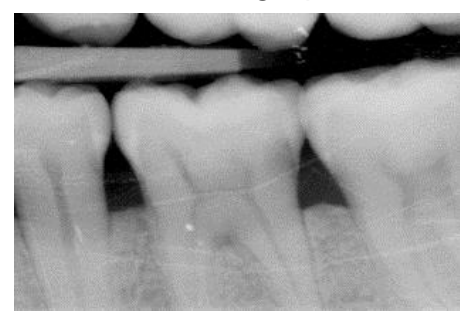

Case 2B Rubber dam isolation

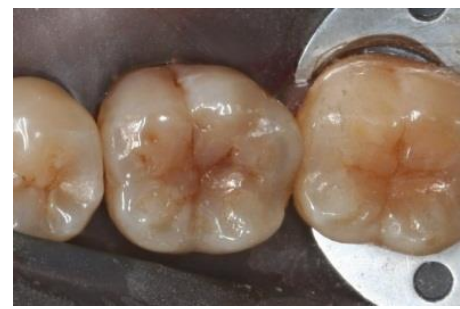

Case 2C Tunnel access

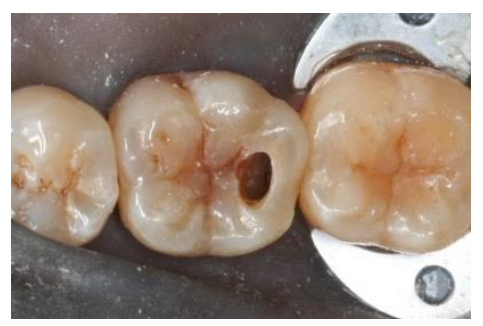

Case 2D Finished restoration

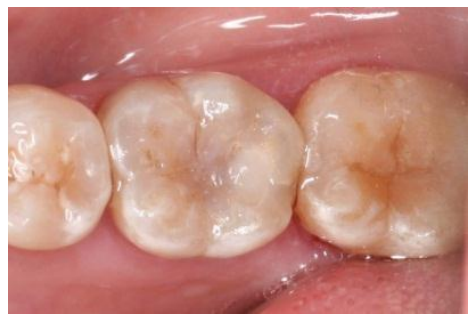

Case 2E Review radiograph

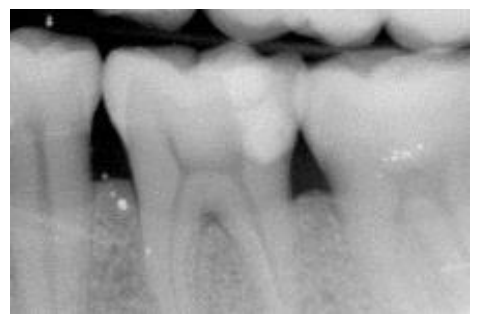


1. Do you practice clinical dentistry including restoration? $(\mathrm{N}=150)$

Yes (90\%; N=135)

No (end of interview) $(10 \% ; \mathrm{N}=15)$

2. Do you practice General Dentistry? $(\mathrm{N}=135)$

Yes $(91 \% ; \mathrm{N}=123)$

No $(9 \% ; N=12)$

3. Do you know Tunnel restoration? $(\mathrm{N}=135)$

Yes $(87 \% ; \mathrm{N}=117)$

No $(13 \% ; N=18)$

4. Are you practicing Tunnel restoration in suitable cases? $(\mathrm{N}=135)$

Yes $(53 \% ; \mathrm{N}=71)$

No $(47 \% ; N=64)$

5. When did you perform your last Tunnel restoration on your patient? $(\mathrm{N}=134)$

Within 6 months $(33 \% ; \mathrm{N}=45)$

6-12 months ago $(15 \% ; \mathrm{N}=20)$

1 to 3 years ago $(10 \% ; N=13)$

More than 3 years $(12 \% ; \mathrm{N}=16)$

Never $(30 \% ; \mathrm{N}=40)$

6. How many Tunnel preparations have you done in last 12 months? $(\mathrm{N}=134)$

Nil $(51 \% ; N=69)$

Within 3 restorations $(21 \% ; \mathrm{N}=28)$

4 - 10 restorations $(19 \% ; \mathrm{N}=25)$

More than 10 restorations $(9 \% ; \mathrm{N}=12)$

7. How many years you have been practicing dentistry? $(\mathrm{N}=134)$

Within 3 years $(11 \% ; \mathrm{N}=14)$

$3-10$ years $(23 \% ; \mathrm{N}=31)$

$11-20$ years $(29 \% ; \mathrm{N}=39)$

More than 20 years $(37 \% ; N=50)$

8. How many hours of continuing dental education you received in the last 12 months? $(\mathrm{N}=135)$

No $(2 \% ; \mathrm{N}=3)$

$1-15$ hours $(32 \% ; \mathrm{N}=43)$

More than 15 hours $(66 \% ; \mathrm{N}=89)$

9. Where did you receive your basic dental training? $(\mathrm{N}=134)$

\begin{tabular}{|c|c|}
\hline Region $(\%, N)$ & Country or Region $(\mathrm{N})$ \\
\hline $\begin{array}{l}\text { Asia } \\
(39 \%, N=52)\end{array}$ & $\begin{array}{l}\text { Bangladesh (19), Burma (3), Hong Kong (3), India (3), Indonesia (7), } \\
\text { Iran (1), Japan (1), Malaysia (3), Nepal (3), Palestine (1), PR China } \\
\text { (1), Philippines (1), Singapore (2), Taiwan (1), Thailand (2), Vietnam (1) }\end{array}$ \\
\hline $\begin{array}{l}\text { Australia \& New Zealand } \\
(7 \%, N=9)\end{array}$ & Australia (7), New Zealand (2) \\
\hline $\begin{array}{l}\text { Africa } \\
(4 \%, N=5)\end{array}$ & Kenya (2), Mozambique (1), Nigeria (1), South Africa (1) \\
\hline $\begin{array}{l}\text { Europe } \\
(30 \%, N=41)\end{array}$ & $\begin{array}{l}\text { Bosnia (3), Bulgaria (2), Denmark (2), Finland (4), France (1), Germany } \\
\text { (3), Greece (9), Italy (2), Norway (2), Portugal (3), Romania (5), Russia } \\
\text { (1), Sweden (1), Switzerland (1), Ukraine (1), UK (1) }\end{array}$ \\
\hline $\begin{array}{l}\text { North America } \\
(4 \%, N=5)\end{array}$ & Canada (4), USA (1) \\
\hline $\begin{array}{l}\text { South America } \\
(16 \%, N=22)\end{array}$ & $\begin{array}{l}\text { Bolivia (3), Brazil (8), Caribbean (5), Columbia (3), Mexico (1), } \\
\text { Venezuela (1) South America (1) }\end{array}$ \\
\hline
\end{tabular}


Table 2 Practice of tunnel restoration and year of dental practice

\begin{tabular}{crrrrr}
\hline \multirow{2}{*}{$\begin{array}{l}\text { Practice } \\
\text { tunnel restoration }\end{array}$} & \multicolumn{4}{c}{ Year of dental practice } & \multirow{2}{*}{ Total } \\
\cline { 2 - 5 } & $<3$ years & $3-10$ years & $11-20$ years & $>20$ years & \\
\hline Yes & $3(21 \%)$ & $13(42 \%)$ & $24(61 \%)$ & $31(62 \%)$ & $71(53 \%)$ \\
No & $11(79 \%)$ & $18(58 \%)$ & $15(39 \%)$ & $19(38 \%)$ & $63(47 \%)$ \\
Total & $14(100 \%)$ & $31(100 \%)$ & $39(100 \%)$ & $50(100 \%)$ & $134(100 \%)$ \\
\hline $\mathrm{P}=0.02$ & & & & &
\end{tabular}

Table 3 Logistic Regression analysis on dentists' practice of tunnel restoration

\begin{tabular}{lccc}
\hline Factors & $\beta(\mathrm{SE})$ & Odd ratio $(95 \% \mathrm{Cl})$ & P-value \\
\hline $\begin{array}{l}\text { Year of dental practice } \\
\quad<3 \text { years }^{\mathrm{a}}\end{array}$ & & & \\
3-10 years & $0.974(0.746)$ & $2.648(0.614-11.430)$ & 0.192 \\
11-20 years & $1.769(0.730)$ & $5.867(1.403-24.523)$ & 0.015 \\
$>20$ years & $1.789(0.714)$ & $5.982(1.477-24.224)$ & 0.012 \\
Constant & $-1.299(0.651)$ & 0.273 & 0.046 \\
\hline
\end{tabular}

$X^{2}<0.001 ;$ d.f. $=2 ; P=1.000$

a Reference category 